$\begin{array}{lllllll}\mathrm{R} & \mathrm{E} & \mathrm{S} & \mathrm{E} & \mathrm{N} & \mathrm{H} & \mathrm{A}\end{array}$

\section{A CIDADE DA}

INFORMALIDADE:

O DESAFIO DAS CIDADES LATINO-AMERICANAS

Pedro Abramo (Org.)

Rio de Janeiro: Livraria Sette Letras/Faperj/

Lincoln Institute, 2003.

Ana Clara Torres Ribeiro (UFRJ)

A coletânea $A$ cidade da informalidades, organizada por Pedro Abramo, aparece num momento particularmente relevante. Existem, atualmente, novas perspectivas para a superação de mecanismos de natureza econômica e político-institucional responsáveis pela reprodução das faces mais cruéis da urbanização. Estas perspectivas decorrem da aprovação do Estatuto da Cidade e da criação do Ministério das Cidades. A coletânea contribui ao tratamento enriquecido de um dos temas centrais da atuação deste Ministério, a regularização fundiária, e para a apropriação social da legislação relativa aos direitos urbanos. Nas palavras de Edésio Fernandes: "a aprovação do importante Estatuto da Cidade consolidou a ordem constitucional quanto ao controle jurídico do desenvolvimento urbano, visando reorientar a ação do Poder Público, do mercado imobiliário e da sociedade (...) Sua efetiva materialização em leis e políticas públicas, porém, dependerá fundamentalmente da ampla mobilização da sociedade brasileira, dentro e fora do aparato estatal" (p.166-7).

Por outro lado, o fato de a coletânea incluir textos de especialistas latino-americanos estimula a reflexão de fenômenos comuns aos países periféricos, tanto relacionados à história da urbanização quanto às formas de enfrentamento das carências sociais, sejam estas concebidas por cada sociedade/governo ou difundidas por agências multilaterais de desenvolvimento. Nesta direção, o livro apresenta uma tensa tessitura de informaçōes e análises, em que a regularização emerge de mobilizações sociais, mas também como solução precária para as necessidades sociais ou, ainda, como estratégia acionada por diferentes atores políticos. Rompe-se, desta maneira, com interpretações da realidade urbana latino-americana que apresentam a regularização como estímulo seguro aos investimentos em habitação ou como "direito", desacompanhado de projetos para o alcance da justiça social.
A coletânea também indica, através de novos processos, a retomada da temática da oposição formal-informal, de longa presença no pensamento latino-americano dedicado ao urbano. Impossível seria, neste sentido, esquecer estudos que, já nos anos 60 , demonstraram os limites político-analíticos desta categoria e, simultaneamente, a relevância dos processos por ela indicados, bastando citar, aqui, os nomes de Aníbal Quijano, José Nun, Paul Singer e Francisco de Oliveira. Grandes esforços teóricos e de análise histórica apoiaram estes estudos e neles tiveram origem. A valorização desta tradição, em diálogo com a coletânea, poderá estimular a reflexão dos rumos tomados pela modernização latino-americana e, especialmente, pelo desenvolvimento urbano. Esta reflexão é indispensável num momento em que a adesão às pautas modernas, como permite ver o artigo de Pedro Abramo sobre as trajetórias familiares de favelados, demonstra a falência (ainda que relativa) de estratégias associadas à educação e à preparação para o trabalho.

$\mathrm{Na}$ atualização do pensamento crítico, será indispensável a análise dos vínculos entre o agravamento das condiçóes urbanas de vida e características do capitalismo periférico, tão bem sugerida pelo estudo transescalar realizado por Susana Pastenack para o caso brasileiro. Será igualmente indispensável o conhecimento aprofundado da experiência urbana popular, como demonstra o artigo de Jane Souto de Oliveira, Denise Britz do Nascimento Silva, José Matias de Lima e Doriam Luis Borges de Melo. Nos anos 90, o diagnóstico da exclusão substituiu o da marginalidade socioespacial. Também neste período, a regularização fundiária adquiriu por vezes, como indicam Emilio Duhau e Maria Cristina Cravino, a anódina fisionomia de uma política pública que mal esconde o desinteresse dos governantes pela proposição de políticas habitacionais abrangentes e pelo controle do, sem exagero retórico, capitalismo selvagem. Como nomear de outra forma uma experiência urbana na qual, como afirma Martim Smolka, "muitos pagam muito pelo pouco que recebem, em contraste aos poucos que recebem muito pelo pouco que entregam" (p.123)?

Neste contexto, existe a possibilidade de que a regularização fundiária alimente-se, como alerta Maria Cristina Cravino, dos discursos e práticas de uma conservadora ideologia comunitária, que esconde conflitos, despolitiza reivindicações e estimula táticas popu- 
lares subalternizantes. Há ainda a possibilidade, segundo Martim Smolka, que a regularização seja acionada por governos indispostos para o enfrentamento amplo e conseqüente da questão social. Em oposição a estas tendências, a coletânea $A$ cidade da informalidade indica que a regularização fundiária e urbanística pode ser conduzida pela análise crítica das formas sociais dominantes (jurídicas e espaciais) e pela valorização da conquista diária da cidade. Deste último ângulo, trata-se de resistências e vitórias parciais que configuram a denominada, por Emilio Duhau, urbanização popular, conceito que reconhece a natureza coletiva da experiência da irregularidade.

Nesta experiência, segundo dados citados por Martim Smolka, encontra-se envolvida, por vezes, mais da metade da população urbana, em precárias condiçôes ambientais, reconhecidas por Alex Kenya Abiko e Fernando Cavallieri. Como denominar esta real estruturação popular da experiência urbana? Será suficiente indicar o seu afastamento da forma dominante, como propõem as noções de informalidade e irregularidade? Estas noções não estimulariam o cômodo esquecimento das múltiplas vivências populares da cidade, que incluem fatos tão distintos quanto favelas (antigas e novas, com diferentes dimensôes), loteamentos clandestinos, ocupações de prédios, assentamentos populares e cortiços, além da experiência extrema da moradia na rua? Como reconhecer os processos econômicos e político-institucionais que unificam as formas urbanas populares, sem pieguismo e ocultamento da dominação e da espoliação? Como apreender, como propõe Pedro Abramo, a complexidade dos elos existentes entre a dinâmica interna das favelas, a dinâmica interfavelas e, ainda, com o entorno imediato de cada assentamento?

$\mathrm{Na}$ coletânea, são identificáveis algumas respostas a estas perguntas na crítica de diretrizes para a política urbana que apenas reconhecem benefícios na regularização; na denúncia da omissão dos governos no delineamento de políticas habitacionais abrangentes; na crítica, como propõe Cláudia Pilla Damasio, a propostas que não incorporem a experiência urbana das classes populares. Estas respostas são indicativas da urgência com que precisam ser desenvolvidas análises estruturais da urbanização latino-americana, orientadas por compromissos com: a ruptura do círculo vicioso que une desigualdade, pobreza e ilegalidade urbana; a democratização do acesso à terra; a garantia universal de condições básicas de vida urbana e o fortalecimento dos sujeitos populares, o que pressupõe muito mais do que a participação usualmente estimulada (e, até mesmo, exigida) nas políticas urbanas. Afinal, como também afirma Edésio Fernandes: "é essencial que se reconheça que em casos como o do Brasil, nos quais a ilegalidade deixou de ser exceção e passou a ser a regra, o fenômeno é estrutural e estruturante dos processos de produção da cidade" (p.139).

Os artigos reunidos na coletânea resistem a propostas de regularização que a apresentam como uma inovadora panacéia para o drama social vivido nas metrópoles da América Latina, desconhecendo, como diz Cláudia Pilla Damasio, os seus vínculos com a indispensável humanização da experiência urbana. Com estes artigos, fica claro que a regularização é um conceito em disputa, que inclui o confronto entre concepções de política urbana. Por outro lado, verifica-se não ser aceitável a regularização como um fim em si mesma, já que os processos indicados por esta noção não geram resultados plenamente previsíveis e controláveis. Além disto, a coletânea permite afirmar que a desregulamentação e/ou a regulamentação simplista e simplificadora, ao gosto das diretrizes neoliberais, não constituem uma saída. De fato, tanto uma regularização resumida à legalização como o simples ajuste estratégico de normas "ao que existe" redundam, por estranhas sinonímias, na indesejável valorização da norma instituída frente a dinâmica da própria sociedade, como se a lei ditasse, por si só, comportamentos coletivos, garantindo a legitimidade aos governantes.

Desta ótica, deixa-se de compreender o marco jurídico como construção política que garante direitos de cidadania, o que estreita a democracia e o espaço público. Porém, como desconhecer que a legalização pode colaborar na redução da violência, retendo a ação de grileiros e os despejos? O núcleo da problemática da regularização é a propriedade, este fundamento da (des)ordem urbana e real sustentáculo da versão dominante do Estado de Direito. Enfrentar este núcleo é também dispor de uma oportunidade para refletir/rever a experiência urbana e, ainda, a organização político-jurídica das relações Sociedade-Estado. O aproveitamento desta oportunidade poderá reaproximar o que décadas de neoliberalismo afastou, isto é, políticas urbanas socialmente justas e projetos dirigidos à inte- 
gração social, implementados nos diferentes níveis de governo.

Não há dúvida de que os países periféricos encontram-se em mais uma encruzilhada. Nesta, os caminhos estão marcados por estratégias para a economia e por percepçôes de democracia. As políticas de regularização estão posicionadas nos termos desta encruzilhada, o que pode ser reconhecido, por exemplo, através de uma comparação entre o artigo de Julio Calderón Cockburn, dedicado à experiência peruana, e os textos de Emilio Duhau e Maria Cristina Cravina. A reflexão crítica dos erros cometidos em políticas de regularização colabora para que sejam superados o clientelismo existente em práticas de legalização e as formas especulativas de enfrentamento da pobreza, como a que agora busca associar, desconhecendo a cultura popular, o acesso à propriedade individual à ação dos bancos privados e ao crédito.

No âmbito dos direitos urbanos, desconhecer culturas - como exposto por Julio Calderón Cockburn no que concerne aos registros de propriedade e, por Edésio Fernandes, com relação aos instrumentos jurídicos - significa impedir a formação de sujeitos sociais. Significa, ainda, conceber falsos projetos, que dispersam investimentos e anulam a face extremamente ativa da experiência popular, demonstrada no dinamismo do mercado informal de terras e moradias. Tal desconhecimento, como indica o texto de Julio Calderón Cockburn, é impeditivo da territorialização de direitos e da emergência de novas territorialidades, efetivamente democráticas. $\mathrm{O}$ mercado abstrato renega o mercado concreto, da mesma maneira que normas jurídicas abstratas rejeitam práticas sociais. Estes espelhos desfocados, presentes em políticas públicas estimuladas por agentes desterritorializados, estimulam uma cegueira ainda mais profunda.

Esta cegueira impede o aprendizado com a experiência das classes populares urbanas dos países periféricos, que constroem cidades e desvendam recursos em ambientes marcados por carência e exclusão. Por que regularizar, apenas, os seus resultados materiais imediatos? Por que não reconhecer propostas latentes (e ainda subordinadas) na urbanização popular, inclusive no que concerne à renovação do direito e do urbanismo? Institucionalizar a carência ou reproduzir a estratégia de indutos e anistia é realmente muito pouco... Reconhecer a potência do "outro" é também admiti-lo na sua capacidade de propor novos universais e, assim, o que afinal é legítimo. As práticas solidárias observadas em favelas constituem elementos morais a serem refletidos no desenho de políticas urbanas, diante do estímulo ao individualismo. De fato, receitas e receituários ou, noutros termos, práticas curativas, no mínimo, não bastam. Os obstáculos existentes à regularização, analisados por Rosana Denaldi e Solange Gonçalves Dias, confirmam esta insuficiência. Também dizem dos limites da regularização, a sua indispensável associação com um plano muito mais abrangente de mudanças institucionais e administrativas.

Há necessidade de uma nova sistematização (e apropriação) dos recursos concentrados nas metrópoles latino-americanas que transforme a própria idéia de regularização e apóie a territorialização de instrumentos jurídicos e urbanísticos. Para tal, é indispensável o diálogo interdisciplinar, valorizador da percepção de direitos originada na experiência popular e das estratégias intergeracionais de sobrevivência e mobilidade social, tratadas nos artigos de Julio Calderón Cockburn e Pedro Abramo. Nestes artigos, surge a indicação de que a experiência da pobreza - dos homens lentos de Milton Santos - resiste aos formuladores das políticas públicas, quando orientados por uma racionalidade que desconhece o tecido urbano. Este desconhecimento, aliás, explica o fracasso de intervenções calcadas numa participação popular, que, simplesmente, não acontece. Trata-se de afastamentos Sociedade-Estado que marcaram a urbanização periférica, com enormes custos sociais, redundando, como esclarece o artigo de Alex Kenia Abiko, em obstáculos financeiros para a administração pública.

Há, realmente, esperança de que a radicalização da democracia integre a urbanização popular à estruturação dominante da cidade? A coletânea demonstra, claramente, que a dicotomia formal-informal precisará ser superada, como afirma Fernando Cavallieri ao indicar a sua simbiose orgânica, da mesma forma que deverá ser superado o recurso a técnicas estatísticas que desconhecem a dinâmica da pobreza. Existe a necessidade de (re)conhecimento profundo dos lugares e de sua intensa vitalidade, indicada no texto de Pedro Abramo e no artigo de Jane Souto de Oliveira, Denise Britz do Nascimento Silva, José Matias de Lima e Dorian Luis Borges de Melo. Deste (re)conhecimento dependerá a esperada renovação da 
política e a multiplicação das formas de vida aceitas e valorizadas, além da superação de barreiras - envolvendo concepções do direito e do urbanismo - até hoje preservadas entre economia e sociedade. Esta superação, exigida pelo conteúdo da coletânea, representa enorme desafio para as disciplinas inscritas no campo do planejamento territorial.

\section{APOLOGIA DA DERIVA: ESCRITOS SITUACIONISTAS SOBRE A CIDADE}

Paola Berenstein Jacques (Org.)

Rio de Janeiro: Casa da Palavra, 2003.

Thais de Bhanthumchinda Portela (UFRJ)

O supra-sumo do espetáculo é o planejamento da felicidade. Raoul Vaneigem, 1961

No período entre guerras, o campo da arquitetura e do urbanismo presenciou o fortalecimento do discurso poético - na busca de soluções dos problemas sociais - e pragmático - no uso da racionalidade técnica para a reconstrução das cidades arrasadas pela guerra propostos nos primeiros CIAMs (Congressos Internacionais de Arquitetura Moderna). Já no pós-guerra, em 1947, no retorno dos Congressos, a cada encontro passou a dominar a figura de Le Corbusier, com o discurso do funcionalismo separatista apresentado na Carta de Atenas (1933) e encaminhado por princípios racionais cartesianos.

Em um contexto de grande destruição que gerava a necessidade de rápida reconstrução dos espaços urbanos e de grandes investimentos na habitação, aliado ao fortalecimento de uma produção industrial de modelo fordista - produção estandardizada, uso de carros, trabalho na fábrica com horários para a produção e para o descanso bem determinados etc. - fizeram que os princípios da Carta de Atenas para o funcionamento da cidade - trabalhar, circular, habitar e recrear - fossem utilizados em larga escala por todo continente europeu, sendo depois transformado em um grande modelo de construção de cidades em diversos países com pretensão a se "modernizar/desenvolver".

Este modernizar as cidades mundo afora seguindo a cartilha do funcionalismo racionalista cartesiano virou cânone, tanto na Academia quanto nos escritórios de projetos, marca do que viria a ser considerado a boa arquitetura e o urbanismo de qualidade. Além disso, na medida em que acontecia a modernização das cidades o Urbanismo fortalecia-se como disciplina, ganhando espaços nos poderes públicos e privados para projetar e planejar as cidades. Aliás, cidade que se prestasse, que fosse desenvolvida, era sinônimo de cidade bem planejada. 